\title{
$\infty \sqrt{1} \begin{aligned} & \text { Stroke and } \\ & \text { Vascular }\end{aligned}$ \\ Endarterectomy versus stenting for stroke prevention
}

\section{A Ross Naylor}

To cite: Naylor AR. Endarterectomy versus stenting for stroke prevention. Stroke and Vascular Neurology 2018;3: e000146. doi:10.1136/svn2018-000146

Received 15 January 2018 Accepted 4 February 2018 Published Online First 24 February 2018

- http://dx.doi.org/10.1136/ svn-2018-000171

Check for updates

The Leicester Vascular Institute, Glenfield Hospital, Leicester, UK

Correspondence to Professor A Ross Naylor; ross.naylor@uhl-tr.nhs.uk

\section{ABSTRACT} clinical practice.

\section{Background}

The European Society for Vascular Surgery (ESVS) has recently prepared updated guidelines for the management of patients with symptomatic and asymptomatic atherosclerotic carotid artery disease, with specific reference to the roles of best medical therapy, carotid endarterectomy (CEA) and carotid artery stenting (CAS). In symptomatic patients, there is a drive towards performing carotid interventions as soon as possible after onset of symptoms. This is because it is now recognised that the highest risk period for recurrent stroke is the first 7-14 days after onset of symptoms. The guidelines advise that there is a role for both CEA and CAS, but the levels of evidence are slightly lower for CAS than for CEA. This is because 30-day risks of death/stroke in the randomised controlled trials (RCTs) were significantly higher than after CEA (especially in the first 7-14 days after onset of symptoms) and there are concerns that the results obtained in the RCTs may not be generalisable into routine clinical practice. In asymptomatic patients, the 2018 ESVS guidelines were the first to recommend that CEA/ CAS should be targeted into a smaller cohort of patients who may be 'higher risk for stroke' on medical therapy. As with symptomatic patients, the ESVS guidelines advise that there is a potential role for both CEA and CAS, but the levels of evidence are again slightly lower for CAS than for CEA. This is because 30-day risks of death/stroke in the two largest RCTs, which used credentialed (experienced CAS practitioners), were only just within the accepted $3 \%$ risk threshold and there remain concerns that the results obtained in RCTs may not be generalisable into routine

\section{SYMPTOMATIC PATIENTS}

Patients are traditionally considered 'recently symptomatic' if they have suffered a carotid territory transient ischaemic attack or stroke within the preceding 6 months. In the 1980 s, there was controversy as to whether carotid endarterectomy (CEA) conferred any benefit over best medical therapy (BMT) in patients with an ipsilateral carotid stenosis. Two landmark randomised controlled trials (RCTs), the European Carotid Surgery Trial (ECST) and the North American Symptomatic Carotid Endarterectomy Trial (NASCET), determined that CEA conferred significant benefit over BMT in patients with an ipsilateral 50\%-99\% internal carotid artery (ICA) stenosis, ${ }^{1}{ }^{2}$ using the NASCET method for measuring carotid stenosis severity. ${ }^{2}$ Subgroup analyses suggested that it was possible to identify certain imaging/ clinical features that were associated with a higher risk of stroke on BMT. ${ }^{3}$ Clinical features of increased benefit conferred by CEA include: increasing age (especially patients aged $>75$ years), recency of symptoms, male sex, hemispheric versus ocular symptoms, cortical versus lacunar stroke and increasing medical comorbidities. ${ }^{3}$ Imaging features associated with an increased risk of stroke on medical therapy include: irregular versus smooth plaques, increasing stenosis severity (but not subocclusion), contralateral occlusion, tandem intracranial disease and a failure to recruit the intracranial collateral circulation. ${ }^{3}$

CEA versus CAS in recently symptomatic patients 30-day outcomes

Nine RCTs recruited symptomatic patients only, ${ }^{4-12}$ while five randomised both symptomatic and asymptomatic patients between CEA and carotid artery stenting (CAS) ${ }^{13-17}$ The most influential national/international RCTs comparing CEA with CAS in symptomatic patients include: the Endarterectomy Versus Angioplasty in Patients with Symptomatic Severe Carotid Stenosis (EVA-3S) trial, the Stent-Protected Angioplasty versus Carotid Endarterectomy (SPACE) study, the International Carotid Stenting Study and the Carotid Revascularisation versus Stenting Trial (CREST). 891118 The principle 30-day endpoints for these four RCTs are detailed in table 1.

Table 2 details ORs (95\% CIs) for 30-day death/stroke in the four main RCTs, where only the symptomatic patients randomised within CREST were included within the meta-analysis.

The Carotid Stent Trialists Collaboration (CSTC) have undertaken a number of subgroup analyses to determine factors associated with poorer outcomes after CAS and CEA, which may influence how individual symptomatic patients are treated.

\section{CAS operator experience}

In EVA-3S, SPACE and ICSS, the 30-day rate of death/stroke was not influenced by lifetime 
Table 130 -day risks following CEA and CAS in trials that randomised $>500$ recently symptomatic patients into EVA-3S, SPACE, International Carotid Stenting Study (ICSS) and CREST ${ }^{81118}$

\begin{tabular}{|c|c|c|c|c|c|c|c|c|}
\hline \multirow[b]{2}{*}{ 30-day risks } & \multicolumn{2}{|c|}{ EVA-3S ${ }^{8}$} & \multicolumn{2}{|l|}{ SPACE $^{9}$} & \multicolumn{2}{|l|}{ ICSS $^{11}$} & \multicolumn{2}{|c|}{ CREST $^{\star 18}$} \\
\hline & $\begin{array}{l}\text { CEA } \\
(n=262)\end{array}$ & $\begin{array}{l}\text { CAS } \\
(n=261)\end{array}$ & $\begin{array}{l}\text { CEA } \\
(n=589)\end{array}$ & $\begin{array}{l}\text { CAS } \\
(n=607)\end{array}$ & $\begin{array}{l}\text { CEA } \\
(n=857)\end{array}$ & $\begin{array}{l}\text { CAS } \\
(n=853)\end{array}$ & $\begin{array}{l}\text { CEA } \\
(n=653)\end{array}$ & $\begin{array}{l}\text { CAS } \\
(n=668)\end{array}$ \\
\hline Death & $1.2 \%$ & $0.8 \%$ & $0.9 \%$ & $1.0 \%$ & $0.8 \%$ & $2.3 \%$ & & \\
\hline Any stroke & $3.5 \%$ & $9.2 \%$ & $6.2 \%$ & $7.2 \%$ & $4.1 \%$ & $7.7 \%$ & $3.2 \%$ & $5.5 \%$ \\
\hline Death/any stroke & $3.9 \%$ & $9.6 \%$ & $6.5 \%$ & $7.4 \%$ & $4.7 \%$ & $8.5 \%$ & $3.2 \%$ & $6.0 \%$ \\
\hline Death/disabling stroke & $1.5 \%$ & $3.4 \%$ & $3.8 \%$ & $5.1 \%$ & $3.2 \%$ & $4 \%$ & & \\
\hline Death/stroke/MI & & & & & $5.2 \%$ & $8.5 \%$ & $5.4 \%$ & $6.7 \%$ \\
\hline Cranial nerve injury & $7.7 \%$ & $1.1 \%$ & & & $5.3 \%$ & $0.1 \%$ & $5.1 \%$ & $0.5 \%$ \\
\hline
\end{tabular}

*Only includes symptomatic patients from CREST.

CAS, carotid artery stenting; CEA, carotid endarterectomy; CREST, Carotid Revascularisation versus Stenting Trial; EVA-3S, Endarterectomy Versus Angioplasty in Patients with Symptomatic Severe Carotid Stenosis; MI, myocardial infarction; SPACE, Stent-Protected Angioplasty versus Carotid Endarterectomy.

CAS practitioner stenting experience $(\mathrm{P}=0.8)$. However, the 30-day rate of death/stroke was significantly higher in symptomatic patients who were treated by CAS practitioners with a low annual CAS volume ( $\leq 3$ procedures per annum; 30-day death/stroke $=10.1 \%$; adjusted risk ratio=2.30 (95\% CI 1.36 to 3.87$)$ ), versus intermediate in-trial CAS volumes (3-6 procedures per annum; 30-day death $/$ stroke $=8.4 \%$; adjusted risk ratio $=1.93(95 \%$ CI 1.14 to 3.27$)$ ), compared with patients treated by higher annual in-trial volume practitioners $(>6$ procedures per year; 30-day death stroke $=5.1 \%) \cdot{ }^{19}$

\section{Effect of age in recently symptomatic patients}

The CSTC pooled data from EVA-3S, SPACE, ICSS and CREST, regarding the effect of increasing age on 30-day death/stroke after CEA and CAS. ${ }^{20}$ There was no evidence of any association between increasing patient age and an increased risk of death/stroke after CEA. However, increasing age was associated with increasing procedural risks in symptomatic patients undergoing CAS. Compared with CAS patients aged $<60$ years, performing CAS in patients aged 70-74 years was associated with a significant increase in 30-day death/stroke (OR 4.01 (95\% CI 2.19 to 7.32)). In CAS patients aged $>80$ years (compared with

Table 2 ORs (95\% Cls) for 30-day death/stroke for CEA versus CAS in EVA-3S, SPACE, ICSS and CREST*

\begin{tabular}{ll}
\hline Trial & OR $(95 \%$ Cl) \\
\hline EVA-3S $^{8}$ & $0.38(0.16$ to 0.84$)$ \\
SPACE $^{9}$ & $0.89(0.55$ to 1.42$)$ \\
ICSS $^{11}$ & $0.53(0.35$ to 0.80$)$ \\
CREST $^{* 18}$ & $0.52(0.29$ to 0.92$)$ \\
Meta-analysis & $0.59(0.42$ to 0.81$)$ \\
\hline
\end{tabular}

*Only symptomatic patients from CREST were included. CAS, carotid artery stenting; CEA, carotid endarterectomy; CREST, Carotid Revascularisation versus Stenting Trial; EVA-3S, Endarterectomy Versus Angioplasty in Patients with Symptomatic Severe Carotid Stenosis; SPACE, Stent-Protected Angioplasty versus Carotid Endarterectomy.
CAS patients $<60$ years), the 30-day risk of death/stroke was increased by 4.15 (95\% CI 2.20 to 7.84 ).$^{20}$

Compared with CEA, 30-day rates of death/stroke were no different after CAS in recently symptomatic patients aged $<70$ years of age. However, there was a progressive increase in the risk of death/stroke after CAS (compared with CEA) which became significant at age 70-74 (OR 2.09 (95\% CI 1.32 to 2.32)), increasing to an OR of 2.43 (95\% CI 1.35 to 4.38 ) for CAS patients aged $>80$ years. ${ }^{20}$

\section{Recency of symptoms}

There is now a worldwide drive towards performing carotid interventions as soon as possible after onset of symptoms. This is because evidence suggests that the risk of stroke in the first 7-14 days after onset of symptoms is significantly higher than previously thought, while delays to CEA are associated with significant reductions in the benefit conferred by CEA. ${ }^{3}$ The CSTC undertook an individual patient meta-analysis of outcomes, stratified for the time delay between symptom onset and undergoing CEA/CAS. ${ }^{21}$ Patients undergoing CAS within $0-7$ days after symptom onset were significantly more likely to suffer a perioperative stroke $(9.4 \%)$, compared with CEA (2.8\%) (OR 3.4 (95\% CI 1.01 to 11.8)). Patients undergoing CAS within 8-14 days after symptom onset were also significantly more likely to suffer a perioperative stroke $(8.1 \%)$ compared with CEA (3.4\%) (OR 2.4 $(95 \%$ CI 1.0 to 5.7$)) .^{21}$

\section{Late outcomes after CEA/CAS in symptomatic patients Late ipsilateral stroke}

Each of the four largest RCTs have shown that once the perioperative period has elapsed, late rates of ipsilateral stroke were no different to CEA, indicating that CAS was as durable as CEA. ${ }^{92-24}$

\section{Late survival}

In CREST, CEA was associated with a 2.3\% risk of perioperative myocardial infarction (MI), which was significantly higher than the 1.1\% observed after CAS (OR 2.0 (95\% CI 
Table 32018 ESVS recommendations for managing patients with symptomatic carotid artery disease ${ }^{28}$

CEA is recommended in patients reporting carotid territory symptoms $<6$ months and who have a $70 \%-99 \%$ carotid stenosis, provided the documented procedural death/stroke rate is $<6 \%$.

CEA should be considered in patients reporting carotid territory symptoms $<6$ months and who have a $50 \%-69 \%$ carotid stenosis, provided the documented procedural death/stroke rate is $<6 \%$.

It is recommended that most patients who have suffered carotid territory symptoms $<6$ months and who are aged $>70$ years and who have $50 \%-99 \%$ stenoses should be treated by CEA, rather than by CAS.

When revascularisation is indicated in patients who with carotid territory symptoms $<6$ months and who are aged $<70$ years, CAS may be considered an alternative to CEA, provided procedural death/stroke rates are $<6 \%$.

When revascularisation is considered appropriate in symptomatic patients with $50 \%-99 \%$ stenoses, it is recommended that this be performed as soon as possible, preferably within 14 days of symptom onset.

Patients who are to undergo revascularisation within the first 14 days after onset of symptoms should undergo CEA, rather than CAS.

In recently symptomatic patients with 50\%-99\% stenoses and anatomical and/or medical comorbidities that are considered by the multidisciplinary team to make them 'higher-risk for CEA, CAS should be considered as an alternative to endarterectomy, provided the documented procedural death/stroke rate is $<6 \%$.

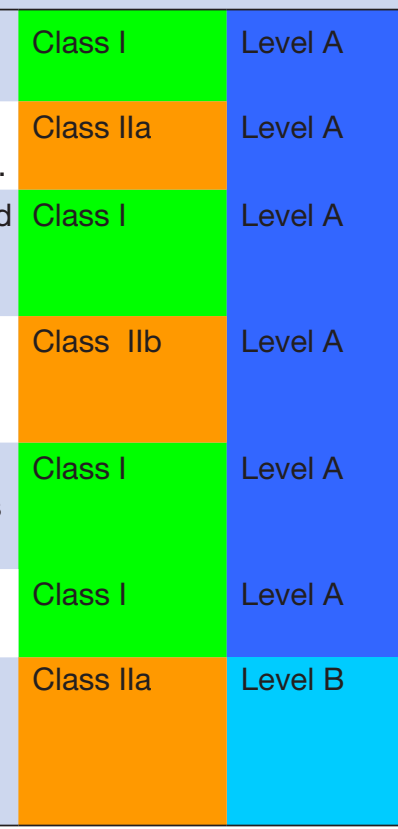

The colour of the text boxes identifies the class and level of evidence.

CAS, carotid artery stenting; CEA, carotid endarterectomy; CREST, Carotid Revascularisation versus Stenting Trial; ESVS, European Society for Vascular Surgery.

1.06 to 3.8$), \mathrm{P}=0.03)) .{ }^{14}$ In a CREST subgroup analysis, patients suffering a perioperative MI faced a threefold increase in late mortality (HR 3.4 (95\% CI 1.7 to 6.0), $\mathrm{P}=0.001) .{ }^{25}$ This was interpreted at the time as meaning that anyone with a history of history of cardiovascular disease should preferentially undergo CAS, rather than CEA. ${ }^{25}$

However, reduced survival after a perioperative MI needs to be balanced against a similar effect of a perioperative stroke on late survival. In CREST, CAS was associated with a $4.1 \%$ risk of perioperative stroke, which was significantly higher than the 2.3\% observed after CEA (OR 1.79 (95\% CI 1.14 to 2.82$), \mathrm{P}=0.01) .{ }^{14}$ In a further CREST subgroup analysis, patients suffering a perioperative stroke also faced a significant increase in late mortality (HR 2.78 (95\% CI 1.63 to 4.76$)) .{ }^{26}$ In a separate meta-analysis, Vincent $e t$ al reported that CAS was associated with a $0.3 \%$ absolute reduction in perioperative MI, which was offset by a $1.8 \%$ increase in perioperative stroke. ${ }^{27}$

\section{Translating evidence into clinical practice in symptomatic} patients

Table 3 summarises the 2018 European Society for Vascular Surgery (ESVS) recommendations for the management of symptomatic carotid disease. ${ }^{28}$ As can be seen, the guidelines advise that there is a role for both CEA and CAS, but the levels of evidence are slightly lower for CAS than for CEA. This is because 30-day risks of death/stroke in the RCTs were significantly higher after CAS than after CEA, and there remain concerns that results obtained in the RCTs may not be generalisable into routine clinical practice. In a systematic review, Paraskevas et al observed that $13 / 18$ administrative dataset registries $(72 \%)$ reported 30-day death/stroke rates in excess of the recommended $6 \%$ risk threshold following CAS in symptomatic patients, while $5 / 18(28 \%)$ reported stroke rates in excess of $10 \%$. This compares with $1 / 18$ registries, which reported 30 -day death/stroke rates exceeding $6 \%$ in patients undergoing CEA. $^{29}$

Table 4 30-day morbidity and mortality in randomised trials comparing CEA and CAS in asymptomatic patients

\begin{tabular}{|c|c|c|c|c|c|c|c|c|c|c|c|}
\hline \multirow[b]{2}{*}{ 30-day outcomes } & \multicolumn{2}{|c|}{ Lexington $^{34}$} & \multicolumn{2}{|c|}{ CREST-1*18 } & \multicolumn{2}{|c|}{ ACT- $1^{35}$} & \multicolumn{3}{|c|}{ SPACE- $2^{33}$} & \multicolumn{2}{|c|}{ Mannheim $^{36}$} \\
\hline & $\begin{array}{l}\text { CEA } \\
n=42\end{array}$ & $\begin{array}{l}\text { CAS } \\
n=43\end{array}$ & $\begin{array}{l}\text { CEA } \\
n=587\end{array}$ & $\begin{array}{l}\text { CAS } \\
n=364\end{array}$ & $\begin{array}{l}\text { CEA } \\
\mathrm{n}=364\end{array}$ & $\begin{array}{l}\text { CAS } \\
n=1089\end{array}$ & $\begin{array}{l}\text { CEA } \\
n=203\end{array}$ & $\begin{array}{l}\text { CAS } \\
n=197\end{array}$ & $\begin{array}{l}\text { BMT } \\
n=113\end{array}$ & $\begin{array}{l}\text { CEA } \\
n=68\end{array}$ & $\begin{array}{l}\text { CAS } \\
n=68\end{array}$ \\
\hline $\begin{array}{l}\text { Death/disabling } \\
\text { stroke }\end{array}$ & $0 \%$ & $0 \%$ & $0.3 \%$ & $0.5 \%$ & $0.6 \%$ & $0.6 \%$ & & & & & \\
\hline
\end{tabular}

${ }^{*}$ Only asymptomatic patients in CREST-1 were included.

ACT-1, Asymptomatic Carotid Trial 1; CAS, carotid artery stenting; CEA, carotid endarterectomy; SPACE, Stent-Protected Angioplasty versus Carotid Endarterectomy. 
Table 52018 ESVS Guidelines: clinical/Imaging features associated with an increased risk of stroke in patients with asymptomatic carotid stenosis treated medically ${ }^{28}$

$\begin{array}{ll}\text { Clinical History of contralateral TIA or stroke } \\ \mathrm{CT} / \mathrm{MRI} & \text { ipsilateral 'silent' infarction }\end{array}$

Ultrasound Stenosis progression $>20 \%$; spontaneous embolisation on TCD; impaired cerebral vascular reserve; large volume plaques $\left(>80 \mathrm{~mm}^{2}\right)$; predominantly echolucent plaques; large juxta-luminal black area $\left(>8 \mathrm{~mm}^{2}\right)$

MRI Intraplaque haemorrhage

ESVS, European Society for Vascular Surgery; TCD, transcranial Doppler ultrasound; TIA, transient ischaemic attack.

\section{ASYMPTOMATIC PATIENTS}

\section{Background}

Patients considered to be asymptomatic have either reported no carotid territory symptoms at any time in the past, or at least 6 months have elapsed since the most recent symptom. Two landmark RCTs, the Asymptomatic Carotid Atherosclerosis Study (ACAS) and the Asymptomatic Carotid Surgery Trial (ACST), determined that CEA conferred a small but significant benefit over BMT in patients with an ipsilateral 60\%-99\% ICA stenosis. ${ }^{30} 31$ Unlike in NASCET and ECST, it was more difficult to identify subgroups of patients who were at higher (or lower) risk of stroke if treated medically. The available data suggested that males gained greater benefit than females and that patients aged $>75$ years gained no benefit from CEA. Interestingly, the presence of a contralateral occlusion and increasing stenosis severity was not associated with an increased risk of late stroke on medical therapy in the RCTs. ${ }^{32}$

\section{CEA versus CAS in asymptomatic patients}

30-day outcomes

Four RCTs exclusively randomised asymptomatic patients, ${ }^{33-36}$ while five included asymptomatic patients within the trial as well as symptomatic patients. ${ }^{13-17}$ In the latter studies, outcomes were not always stratified for symptom status. Table 4 details the main 30-day outcomes from five RCTs where data were provided for asymptomatic patients.

\section{Late outcomes}

The Lexington study, CREST and ACT-1 observed that once the perioperative period had elapsed, there was no difference in rates of late ipsilateral stroke, suggesting that CAS was as durable as CEA. ${ }^{22} 3435$

\section{Translating evidence into clinical practice}

Unlike the symptomatic RCTs, which continue to retain the same relevance in the modern era, there are concerns that the ACAS and ACST trials (which recruited patients up to 25 years ago) may not be as relevant as when published in 1995 and 2004, respectively. ${ }^{30}{ }^{31}$ This is mainly because of increasing evidence that the risk of
Table 62018 ESVS recommendations for managing patients with asymptomatic carotid artery disease ${ }^{28}$

In 'average surgical risk' patients with an asymptomatic $60 \%-99 \%$ stenosis, CEA should be considered in the presence of $1+$ imaging characteristics that may be associated with an increased risk of late ipsilateral stroke*, provided perioperative stroke/death rates are $<3 \%$ and the patient's life expectancy exceeds 5 years.

In 'average surgical risk' patients with an asymptomatic 60\%-99\% stenosis in the presence of 1+ imaging characteristics that may be associated with an increased risk of late ipsilateral stroke $^{\star}$, CAS may be an alternative to CEA, provided perioperative stroke/ death rates are $<3 \%$ and the patient's life expectancy exceeds 5 years.

CAS may be considered in selected asymptomatic patients who have been

Class Ila Level B deemed by the multidisciplinary team to be 'high-risk for CEA' and who have an asymptomatic 60\%-99\% stenosis in the presence of $1+$ imaging characteristics that may be associated with an increased risk of late ipsilateral stroke*, provided procedural risks are $<3 \%$ and the patient's life expectancy exceeds 5 years.

*See table 5 for clinical/imaging features.

The colour of the text boxes identifies the class and level of evidence.

CAS, carotid artery stenting; CEA, carotid endarterectomy; ESVS, European Society for Vascular Surgery.

stroke on 'modern BMT' may not be as high as previously thought and there is evidence that the annual risk of stroke on BMT may have declined by about $70 \%$ since ACAS first reported in 1995. ${ }^{32} 37$ These concerns were recognised in the 2018 ESVS carotid guidelines where it was recommended that only patients with one or more clinical and/or imaging features that might make them higher risk for stroke on BMT should be considered for CEA or CAS. ${ }^{28}$ These imaging and clinical criteria are summarised in table 5 and readers are referred to the 2018 ESVS carotid guidelines, where greater detail has been provided regarding the magnitude of benefit (in terms of stroke reduction) associated with each of these clinical/imaging parameters. ${ }^{28}$

While this decision to target CEA/CAS into a smaller cohort of asymptomatic patients has not always met with universal approval, ${ }^{38}$ it was necessary as (currently) $95 \%$ of all asymptomatic patients undergoing a carotid intervention ultimately undergo an unnecessary intervention. ${ }^{32}$ Interestingly, the American Heart Association guidelines advise that only 'highly selected' asymptomatic patients should be 
considered for CEA (or CAS), but they have never defined exactly what 'highly selected' means. ${ }^{39}$

Table 6 summarises the 2018 ESVS recommendations for the management of asymptomatic carotid disease. As with symptomatic patients, the ESVS guidelines advise that there is a potential role for both CEA and CAS, but the levels of evidence are slightly less for CAS than for CEA. This is because 30-day risks of death/stroke in the largest RCTs, which used credentialed (experienced CAS practitioners), ${ }^{1835}$ were only just within the accepted $3 \%$ risk threshold and there remain concerns that the results obtained in the RCTs may not be generalisable into routine clinical practice. In a systematic review, Paraskevas et al observed that $9 / 21$ administrative dataset registries (43\%) reported 30-day death/stroke rates in excess of the recommended $3 \%$ risk threshold after CAS in asymptomatic patients, while $7 / 21(33 \%)$ reported stroke rates in excess of $4 \%$. This compares with $1 / 21$ registries which reported 30-day death/stroke rates exceeding 3\% in patients undergoing CEA. ${ }^{29}$

Funding This research received no specific grant from any funding agency in the public, commercial or not-for-profit sectors.

Competing interests None declared.

Provenance and peer review Commissioned; internally peer reviewed.

Guest chief editor J David Spence

Open access This is an open access article distributed in accordance with the Creative Commons Attribution Non Commercial (CC BY-NC 4.0) license, which permits others to distribute, remix, adapt, build upon this work non-commercially, and license their derivative works on different terms, provided the original work is properly cited and the use is non-commercial. See: http://creativecommons.org/ licenses/by-nc/4.0/

(C) Article author(s) (or their employer(s) unless otherwise stated in the text of the article) 2018. All rights reserved. No commercial use is permitted unless otherwise expressly granted.

\section{REFERENCES}

1. European Carotid Surgery Trialists' Collaborative Group. MRC European Carotid Surgery Trial: interim results for symptomatic patients with severe $(70-99 \%)$ or with mild $(0-29 \%)$ carotid stenosis. European Carotid Surgery Trialists' Collaborative Group. Lancet 1991;337:1235-43.

2. North American Symptomatic Carotid Endarterectomy Trial Collaborators. Beneficial effect of carotid endarterectomy in symptomatic patients with high grade carotid stenosis. N Engl J Med 1991;325:445-53.

3. Naylor AR, Sillesen H, Schroeder TV. Clinical and imaging features associated with an increased risk of early and late stroke in patients with symptomatic carotid disease. Eur J Vasc Endovasc Surg 2015;49:513-23.

4. Naylor AR, et al. Randomized study of carotid angioplasty and stenting versus carotid endarterectomy: a stopped trial. J Vasc Surg 1998;28:326-34.

5. Alberts MJ. Results of a multicentre prospective randomized trial of carotid artery stenting vs carotid endarterectomy. Stroke 2001;32:325.

6. Brooks WH, McClure RR, Jones MR, et al. Carotid angioplasty and stenting versus carotid endarterectomy: randomized trial in a community hospital. J Am Coll Cardiol 2001;38:1589-95.

7. Hoffmann A, Engelter S, Taschner C, et al. Carotid artery stenting versus carotid endarterectomy - a prospective randomized controlled single-centre trial with long-term follow up (BACASS). Schweizer Archiv für Neurologie und Psychiatrie 2008;159:84-9.

8. Mas JL, Trinquart L, Leys D, et al. Endarterectomy Versus Angioplasty in Patients with Symptomatic Severe Carotid Stenosis (EVA-3S) trial: results up to 4 years from a randomised, multicentre trial. Lancet Neurol 2008;7:885-92.
9. Eckstein HH, Ringleb P, Allenberg JR, et al. Results of the StentProtected Angioplasty versus Carotid Endarterectomy (SPACE) study to treat symptomatic stenoses at 2 years: a multinational, prospective, randomised trial. Lancet Neurol 2008;7:893-902.

10. Endovascular versus surgical treatment in patients with carotid stenosis in the Carotid and Vertebral Artery Transluminal Angioplasty Study (CAVATAS): a randomised trial. Lancet 2001;357:1729-37.

11. Ederle J, Dobson J, Featherstone RL, et al. Carotid artery stenting compared with endarterectomy in patients with symptomatic carotid stenosis (International Carotid Stenting Study): an interim analysis of a randomised controlled trial. Lancet 2010;375:985-97.

12. Steinbauer MG, Pfister K, Greindl M, et al. Alert for increased longterm follow-up after carotid artery stenting: results of a prospective, randomized, single-center trial of carotid artery stenting vs carotid endarterectomy. J Vasc Surg 2008;48:93-8.

13. Yadav JS, Wholey MH, Kuntz RE, et al. Protected carotid-artery stenting versus endarterectomy in high-risk patients. N Engl J Med 2004;351:1493-501.

14. Brott TG, Hobson RW, Howard G, et al. Stenting versus endarterectomy for treatment of carotid-artery stenosis. $\mathrm{N} \mathrm{Engl} \mathrm{J}$ Med 2010;363:11-23.

15. Ling F, Jiao LQ. Preliminary report of trial of endarterectomy versus stenting for the treatment of carotid atherosclerotic stenosis in China (TESCAS-C). Chinese J Cerebrovasc Dis 2006;3:4-8.

16. Wang P, Liang C, Du J, Du C, et al. Effects of carotid endarterectomy and carotid artery stenting on high-risk carotid stenosis patients. Pak J Med Sci 2013;29:1315-8.

17. Kuliha M, Roubec M, Procházka V, et al. Randomized clinical trial comparing neurological outcomes after carotid endarterectomy or stenting. Br J Surg 2015;102:194-201.

18. Silver FL, Mackey A, Clark WM, et al. Safety of stenting and endarterectomy by symptomatic status in the Carotid Revascularization Endarterectomy Versus Stenting Trial (CREST). Stroke 2011;42:675-80.

19. Calvet D, Mas JL, Algra A, et al. Carotid stenting: is there an operator effect? A pooled analysis from the carotid stenting trialists' collaboration. Stroke 2014;45:527-32.

20. Howard G, Roubin GS, Jansen O, et al. Association between age and risk of stroke or death from carotid endarterectomy and carotid stenting: a meta-analysis of pooled patient data from four randomised trials. Lancet 2016;387:1305-11.

21. Rantner B, Goebel G, Bonati LH, et al. The risk of carotid artery stenting compared with carotid endarterectomy is greatest in patients treated within 7 days of symptoms. J Vasc Surg 2013;57:619-26.

22. Brott TG, Howard G, Roubin GS, et al. Long-term results of stenting versus endarterectomy for carotid-artery stenosis. N Engl J Med Overseas Ed 2016;374:1021-31.

23. Bonati LH, Dobson J, Featherstone RL, et al. for the International Carotid Stenting Study investigators. Long-term outcomes after stenting versus endarterectomy for treatment of symptomatic carotid stenosis: the International Carotid Stenting Study (ICSS) randomized trial. Lancet 2015;385:529-38.

24. Mas JL, Arquizan C, Calvet D, et al. Long-term follow-up study of endarterectomy versus angioplasty in patients with symptomatic severe carotid stenosis trial. Stroke 2014:45:2750-6.

25. Blackshear JL, Cutlip DE, Roubin GS, et al. Myocardial infarction after carotid stenting and endarterectomy: results from the carotid revascularization endarterectomy versus stenting trial. Circulation 2011;123:2571-8.

26. Hill MD, Brooks W, Mackey A, et al. Stroke after carotid stenting and endarterectomy in the Carotid Revascularization Endarterectomy versus Stenting Trial (CREST). Circulation 2012;126:3054-61.

27. Vincent S, Eberg M, Eisenberg MJ, et al. Meta-Analysis of Randomized Controlled Trials Comparing the Long-Term Outcomes of Carotid Artery Stenting Versus Endarterectomy. Circ Cardiovasc Qual Outcomes 2015;8:S99-S108.

28. Naylor AR, Ricco JB. Editor's Choice -Management of atherosclerotic carotid and artery disease : 2017 Clinical practice guidelines of the European Society for Vascular Surgery (ESVS)". Eur $J$ Vasc Endovasc Surg 2018;55:142-3.

29. Paraskevas KI, Kalmykov EL, Naylor AR. Stroke/death rates following carotid Artery stenting and carotid endarterectomy in contemporary administrative dataset registries: A systematic review. Eur J Vasc Endovasc Surg 2016;51:3-12.

30. Executive Committee for the Asymptomatic Carotid Atherosclerosis Study. Endarterectomy for asymptomatic carotid artery stenosis. JAMA 1995;273:1421-8.

31. MRC Asymptomatic Carotid Surgery Trial (ACST) Collaborative Group. Prevention of disabling and fatal strokes by successful carotid endarterectomy in patients without recent neurological symptoms: randomised controlled trial. Lancet 2004;363:1491-502. 
32. Naylor AR, Schroeder TV, Sillesen H. Clinical and imaging features associated with an increased risk of late stroke in patients with asymptomatic carotid disease. Eur J Vasc Endovasc Surg 2014:48:633-40.

33. Eckstein HH, Reiff T, Ringleb P, et al. SPACE-2: A missed opportunity to compare carotid endarterectomy, carotid stenting, and best medical treatment in patients with asymptomatic carotid stenoses. Eur J Vasc Endovasc Surg 2016;51:761-5.

34. Brooks WH, McClure RR, Jones MR, et al. Carotid angioplasty and stenting versus carotid endarterectomy for treatment of asymptomatic carotid stenosis: a randomized trial in a community hospital. Neurosurgery 2004;54:318-25.

35. Rosenfield K, Matsumura JS, Chaturvedi S, et al. Randomized Trial of Stent versus Surgery for Asymptomatic Carotid Stenosis. N Engl J Med 2016;374:1011-20.
36. Mannheim D, Karmeli R. A prospective randomized trial comparing endarterectomy to stenting in severe asymptomatic carotid stenosis. J Cardiovasc Surg 2017;58:814-7.

37. Hadar N, Raman G, Moorthy D, et al. Asymptomatic carotid artery stenosis treated with medical therapy alone: temporal trends and implications for risk assessment and the design of future studies. Cerebrovasc Dis 2014;38:163-73.

38. Eckstein HH. European Society for Vascular Surgery Guidelines on the Management of Atherosclerotic Carotid and Vertebral Artery Disease. Eur J Vasc Endovasc Surg 2018;55:1-2.

39. Meschia JF, Bushnell C, Boden-Albala B, et al. Guidelines for the primary prevention of stroke: a statement for healthcare professionals from the American Heart Association/American Stroke Association. Stroke 2014;45:3754-832. 